\title{
Estudo do Uso de Plastificantes de Fontes Renovável em Composições de PVC
}

Emerson Madaleno Braskem S/A

Derval dos S. Rosa UFABC

Sonia F. Zawadzki, Tiago H. Pedrozo, Luiz P. Ramos UFPR

Resumo: Polímeros sintéticos são largamente utilizados em diversos produtos devido às suas propriedades físicas, químicas e facilidade de transformação. O poli(cloreto de vinila), conhecido como PVC, é um dos polímeros mais versáteis desenvolvidos pelo homem, de grande utilidade para a sociedade moderna. Suas aplicações incluem: janelas, calhas de chuva, revestimentos de paredes, portas, papel de parede, mangueiras, brinquedos, calçados, bolsas de sangue e tubos para condução de água. Em todas estas aplicações são utilizados aditivos junto à resina de PVC, sendo que um dos aditivos mais utilizados é o plastificante. Este estudo apresenta a análise comparativa de formulações flexíveis de PVC, baseada em dois plastificantes de origem renovável (óleo vegetal modificado - OVM e óleo vegetal modificado e epoxidado - OVME), e também dois plastificantes petroquímicos convencionais, di(2-etilhexil) ftalato - (DEHP) ou DOP e di(2-etilhexil) adipato - (DEHA) ou DOA. Não foram observadas diferenças significativas entre as propriedades mecânicas das formulações. Os diferentes plastificantes demonstram influenciar na dureza e resistência química das formulações, sendo que o grupo epóxi e a maior massa molar no plastificante vegetal apresentam maior compatibilidade com a resina de PVC. A análise de MEV apresenta uma provável exudação do plastificante OVM da matriz do PVC.

Palavras-chave: PVC, plastificante, fonte renovável.

\section{Study of the Use of Plasticizer from Renewable Sources in PVC Compositions}

Abstract: Synthetic polymers have been widely used in manufactured products because of their physical and chemical properties and low cost of production. Poly(vinyl chloride), called PVC, is a versatile, inexpensive plastic whose use has become pervasive in modern society. Its applications include window frames, rain gutters, wall paneling, doors, wallpapers, flooring, garden furniture, toys, blood bags and pipes. In all of these applications additives are used, with plasticizers being among the most important. This work shows a comparative study among distinct compositions of flexible PVC - based on two vegetable plasticizers from renewable sources (modified vegetable oil - OVM and epoxidized modified vegetable oil - OVME), in addition to two conventional petrochemical plasticizers, called di(2-ethylhexyl) phthalate-(DEHP) and di(2-ethylhexyl) adipate-(DEHA). No significant differences were observed in the mechanical behavior of the compositions evaluated. The plasticizers affected the hardness and chemical resistance to n-heptane for the compositions. The epoxi group and the high molar mass from vegetable plasticizers showed better compatibility with the PVC resin. The analyses by SEM showed a probable exudation of OVM from the PVC matrix.

Keywords: PVC, plasticizers, renewable source.

\section{Introdução}

O Poli(cloreto de vinila) - PVC é considerado um dos polímeros mais versáteis devido sua possibilidade em reagir com diferentes aditivos, o que pode alterar suas características dentro de um amplo espectro de propriedades, apresentando-se desde o rígido ao extremamente flexível e, conseqüentemente, sendo utilizado em aplicações que vão desde tubos e perfis rígidos, para uso na construção civil, até brinquedos e filmes flexíveis utilizados no acondicionamento de alimentos, sangue, soro e plasma. Esta versatilidade também é verificada nos processos de transformação que o PVC formulado pode sofrer, podendo ser injetado, calandrado, extrudado ou até mesmo espalmado ${ }^{[1]}$.

Um dos mais importantes aditivos para o PVC é o plastificante, que confere flexibilidade a este polímero. 
O uso de plastificantes no PVC é conhecido desde os anos 50, sendo empregado em vários produtos, como filmes alimentícios, mangueiras, laminados, brinquedos e calçados, sendo os da família dos ftalatos de maior uso mundial. Porém, alguns ftalatos apresentam restrição de uso para algumas aplicações, já que estudos em roedores demonstraram potencial carcinogênico e mutagênico nestes ${ }^{[2]}$. Para o IARC (International Agency for Research on Câncer), órgão científico ligado à OMS (Organização Mundial da Saúde), o Ftalato de dioctila (DOP) ou di(2-etilhexil) ftalato (DEHP) é, desde 2000, classificado como uma "substância que não pode ser considerada como causadora do câncer nos seres humanos". Mesmo tal recomendação é crescente a restrição do uso desta substância como plastificante para polímeros e elastômeros no mundo todo ${ }^{[3]}$.

Desta forma, a busca por plastificantes alternativos aos ftalatos no mercado mundial foi um dos importantes motivadores para a realização deste estudo. O uso de plastificantes de origem vegetal, neste caso proveniente do óleo de milho, em composições com o PVC foi o eixo principal para a realização desta pesquisa, na qual foram avaliadas características físicas, térmicas e químicas.

Existem duas teorias principais que procuram explicar a ação do plastificante sobre o PVC, conferindo-lhe flexibilidade: teoria da lubrificação e teoria do gel.

A teoria da lubrificação desenvolvida a partir do trabalho de Kirk-Patrick et al. É comentada por Rodolfo et al. ${ }^{[1]} \mathrm{e}$ Nass e Heiberger ${ }^{[4]}$ e está ligada à diminuição da resistência do polímero à deformação como resultado da diminuição do atrito intermolecular existente entre os segmentos poliméricos e agindo como lubrificante facilitando o movimento das macromoléculas umas sobre as outras (lubrificação interna).

A teoria do gel desenvolvida a partir do trabalho de Doolittle apud Rodolfo et al. ${ }^{[1]}$ propõe que os plastificantes atuam sobre as ligações dipolo-dipolo e forças de van der Waals, atenuando-as, e, conseqüentemente, reduzindo arigidez do polímero. A atenuação destas interações ocorre uma vez que as moléculas de plastificante, ao se posicionarem entre as cadeias de PVC, aumentam a distância entre as mesmas. A força de atração eletrostática é inversamente proporcional à distância entre as cargas elétricas; portanto, o aumento da distância intermolecular atenua a força de atração entre as cadeias, flexibilizando o polímero. Em outras palavras, a presença das moléculas do plastificante, em meio às cadeias poliméricas do PVC, promove a "quebra" das ligações dipolo-dipolo entre as últimas, criando novos dipolos entre o PVC e o plastificante ${ }^{[5]}$.

A Figura 1 proposta por Leuchs apud Titow ${ }^{[6]}$ mostra a estrutura química de um ftalato entre as cadeias de PVC, na qual as cargas eletrostáticas são minimizadas pela presença do aditivo.

As fontes de obtenção de plastificantes para o PVC, em sua grande maioria, são ésteres ou poliésteres, incluindo outros como ácidos adípicos, fosfóricos, sebáceos, trimelíticos ou azeláticos, sem mencionar os de origem natural.

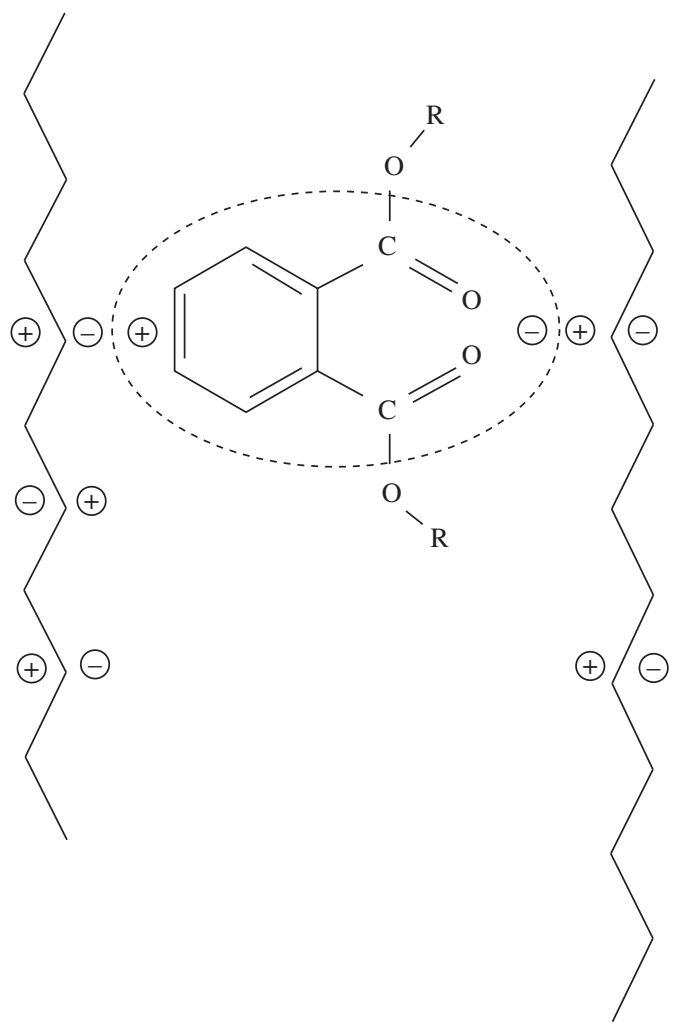

Figura 1. Representação química de um plastificante à base de ftalato sofrendo desbalanceamento eletrostático devido à eletronegatividade da cadeia do $\mathrm{PVC}^{[6]}$.

Os tipos mais conhecidos de plastificantes de fontes naturais para o uso com o PVC são produzidos pela epoxidação de óleos vegetais ou de ésteres insaturados, sendo que esta reação emprega, em geral, um perácido orgânico. Este é o caso do óleo de soja epoxidado, que apresenta massa molar de $1.000 \mathrm{~g} \cdot \mathrm{mol}^{-1} \mathrm{e}$ viscosidade de $500 \mathrm{mPa}$.s a $20^{\circ} \mathrm{C}$, e é largamente utilizado na indústria do PVC, devido às suas características de sinergia com os estabilizantes térmicos para o PVC, além do seu efeito como plastificante secundário, que possuem menor miscibilidade e compatibilidade com a resina de PVC, podendo sofrer migração ou exsudação ${ }^{[1,7]}$.

Este mesmo processo pode ser empregado para outras fontes de ácidos graxos, como por exemplo, os demais óleos vegetais insaturados e até as gorduras animais. Pedrozo $^{[8]}$ desenvolveu a epoxidação do éster do óleo de milho e criou um plastificante que poderá apresentar grande interesse comercial e técnico ao mercado do PVC. Para o desenvolvimento utilizou-se do óleo extraído do germe do milho e refinado industrialmente, cuja composição básica é retratada na Tabela 1 .

A partir do óleo de milho, Pedrozo ${ }^{[8]}$ efetuou sua esterificação e, em uma destas, a epoxidação posteriormente e são apresentadas nas Figuras 2 e 3.

Krauskopf ${ }^{9]}$ fez uma abordagem, em seu estudo, sobre as alternativas aos plastificantes à base de ftalatos para uso com polímeros polares, com ênfase ao PVC. Os plastificantes ftálicos apresentam expressivo histórico frente às diversas 
Tabela 1. Principais ácidos graxos encontrados na composição do óleo de milho ${ }^{[8]}$.

\begin{tabular}{ccccccc}
\hline Fonte & $\mathbf{N}^{\circ}$ de Iodo & Palmítico (16:0) & Esteárico (18:0) & Oléico (18:1) & Linoléico (18:2) & Linolênico (18:3) \\
\hline Milho & $111-130$ & $5,5 \%$ & $1,5 \%$ & $44,0 \%$ & $48,0 \%$ & $1,0 \%$ \\
\hline
\end{tabular}

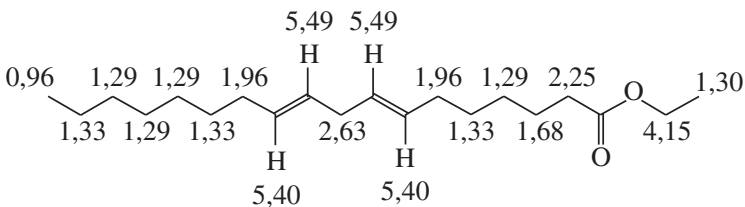

Figura 2. Representação esquemática de estrutura provável do éster do óleo de milho, neste trabalho denominado como OVM (óleo vegetal modificado)

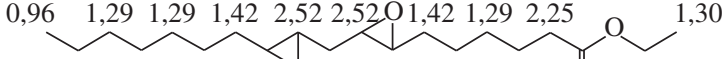

$$
\begin{aligned}
& \begin{array}{llllllllllll}
1,33 & 1,29 & 1,29 & 2,52 & 01,55 & 2,52 & 1,29 & 1,68
\end{array}
\end{aligned}
$$

Figura 3. Representação esquemática de estrutura provável do éster do óleo de milho epoxidado, neste trabalho denominado como OVME (óleo vegetal modificado epoxidado)

aplicações para os setores hospitalar, farmacêutico e alimentício. E alguns destes setores têm adotado medidas cautelosas na busca de alternativas aos plastificantes ftálicos, que têm sido muito questionados nos últimos anos. Oefeito dos plastificantes ftálicos e outros plastificantes sobre o aspecto de saúde humana, segurança e meio ambiente tem intensamente sido estudado nos últimos trinta anos. É fato que os ftalatos são uma das classes de compostos químicos mais estudados em todo o mundo para este fim e são essencialmente inócuos, desde que presentes em dosagens adequadas e não expostos em condições extremas. É importante salientar, ainda, que muitos destes estudos são conflitantes entre si, principalmente na busca de regulamentações para os mercados de brinquedos, produtos hospitalares e alimentício.

Costa e Rosa ${ }^{[10]}$ estudou o uso de blendas de PVC com poli(caprolactona), PCL, em substituição às formulações de PVC com DOP ou adipato de di(etil hexila), DOA, para uso em aplicações alimentícias, buscando reduzir aspectos toxicológicos ambientais, já que a PCL é considerada como um polímero biodegradável. Embora tenha sido verificada boa miscibilidade e compatibilidade entre os componentes desta mistura, a biodegradação das composições não foi possível.

\section{Experimental}

Os materiais utilizados neste trabalho estão descritos a seguir:

1) Poli (cloreto de vinila) Norvic ${ }^{\circledR}$ SP $1300 \mathrm{HP}^{[1]}$, com valor $\mathrm{K}$ de $71 \pm 1$, fornecido pela Braskem S/A.

2) Ftalato de dioctila, DOP, com massa molar $390,5 \mathrm{~g} \cdot \mathrm{mol}^{-1}$, fornecido pela Scandiflex do Brasil S/A ${ }^{[12]}$.

3) Adipato de dioctila, DOA, com massa molar 370,6 g. $\mathrm{mol}^{-1}$, fornecido pela Scandiflex do Brasil $\mathrm{S} / \mathrm{A}^{[12]}$
4) Plastificante OVM (Óleo Vegetal Modificado), com massa molar 296,5 g. $\mathrm{mol}^{-1}$ fornecido pela Corn Products do Brasil e Universidade Federal do Paraná ${ }^{[8]}$.

5) Plastificante OVME (Óleo Vegetal Modificado e Epoxidado), com massa molar 320,3 g. $\mathrm{mol}^{-1}$, fornecido pela Corn Products do Brasil e Universidade Federal do Paraná ${ }^{[8]}$.

6) Naftosafe DXC 1198, estabilizante térmico à base de sais metálicos de Estearatos de cálcio e zinco, fornecido pela Chemson Ltda.

7) Drapex 6.8, óleo de soja epoxidado, com massa molar de 944 g.mol ${ }^{-1}$, fornecido pela Inbra Indústrias Químicas Ltda.

8) "Antifogging" Logosplast 3160 EA e lubrificante externo Logosplast 3167, fornecidos pela Logos Química, ambos derivados de ácido graxo.

As composições foram preparadas utilizando as quantidades dos componentes indicadas na Tabela 2, mostrada abaixo. O procedimento para a realização das misturas é descrito a seguir.

\section{Preparação das misturas}

A resina de PVC e os aditivos foram misturados nas proporções descritas na Tabela 2 em misturador intensivo da marca Mecanoplast ML9, nas condições de 1.500 rpm, a $110^{\circ} \mathrm{C}$ e resfriado posteriormente a $40^{\circ} \mathrm{C}$.

\section{Espectroscopia na região do infravermelho}

Foi utilizado o equipamento de FTIR para a caracterização dos diferentes plastificantes. Para esta análise utilizou-se o equipamento da marca Thermo Electron Corporation modelo Nicolet 4700 FTIR com transformada de Fourier, realizadas por transmissão com 32 leituras, intervalos de varredura $1 \mathrm{~cm}^{-1} \mathrm{e}$ faixa de varredura $400-4000 \mathrm{~cm}^{-1}$.

Tabela 2. Formulações preparadas em PCR

\begin{tabular}{lcccc}
\hline \multicolumn{1}{c}{ Material } & $\mathbf{1}$ & $\mathbf{2}$ & $\mathbf{3}$ & $\mathbf{4}$ \\
\hline Resina de PVC VK70 & 100 & 100 & 100 & 100 \\
DOP & 40 & 0 & 0 & 0 \\
DOA & 0 & 40 & 0 & 0 \\
Óleo vegetal modificado & 0 & 0 & 40 & 0 \\
Óleo vegetal modificado epoxidado & 0 & 0 & 0 & 40 \\
Óleo de soja epoxidado & 5 & 5 & 5 & 5 \\
Estabilizante térmico Ca/Zn & 1,5 & 1,5 & 1,5 & 1,5 \\
Anti fogging & 1,5 & 1,5 & 1,5 & 1,5 \\
Lubrificante & 1,2 & 1,2 & 1,2 & 1,2 \\
\hline
\end{tabular}

PCR = partes cem de resina (também pode-se encontrar $\mathrm{phr}=$ parts hundred resin). 


\section{Ensaios de tração}

As propriedades mecânicas determinadas, segundo a norma ASTM D-638 ${ }^{[13]}$, foram: resistência à tração, módulo de elasticidade e alongamento na ruptura, utilizando o equipamento de ensaio universal modelo MTS Alliance $\mathrm{RT} / 5$, com célula de carga de $50 \mathrm{kN}$, velocidade da travessa de $50 \mathrm{~mm} / \mathrm{min}$. e distância entre garras de $50 \mathrm{~mm}$ com auxilio de um extensômetro mecânico. Foram utilizados 10 corposde prova do tipo IV para cada formulação ensaiada.

\section{Propriedades reológicas}

A determinação das características de gelificação e plastificação dos compostos e sua viscosidade foram realizadas em Reômetro de torque da marca Haake Polylab System. Para as condições de ensaio utilizou-se a câmara de mistura de $30 \mathrm{~cm}^{3}$, com dois rotores contra-rotantes, temperatura da câmara de $130{ }^{\circ} \mathrm{C}$; velocidade de $40 \mathrm{rpm}$ e massa de $65 \mathrm{~g}$ por 15 minutos. A base para os ensaios foi a ASTM D-2396 $6^{[14]}$.

\section{Dureza}

As propriedades de dureza foram determinadas segundo a ASTM D-2240 ${ }^{[15]}$ utilizando equipamento de dureza Bareiss GmbH tipo BS61 Shore A. Para a determinação desta propriedade foram preparados corpos de prova cilíndricos de $8 \mathrm{~cm}$ de diâmetro e $3 \mathrm{~mm}$ de espessura. Foram realizadas 5 medições para cada formulação.

\section{Resistência química em n-heptano}

Este ensaio se baseia na portaria $\mathrm{n}^{\circ} 105$ da Agência Nacional de Vigilância Sanitária (ANVISA) ${ }^{[16]}$ que avalia a migração total dos aditivos presentes nas embalagens em contato direto com alimentos. O solvente n-heptano é empregado como simulante em produtos gordurosos. O ensaio consiste na determinação da variação da massa do corpo-deprova com dimensões de $100 \times 100 \times 3 \mathrm{~mm}$, quando imerso em solvente n-heptano à temperatura ambiente. As amostras foram pesadas em balança analítica de precisão 0,0001 $\mathrm{g}$ modelo Adventure AR2140, Ohaus Corporation e imersas em recipiente fechados contendo o solvente n-heptano PA. Ao final de 24 e 168 horas de ensaio os corpos-de-prova foram retirados e lavados em água destilada, com o intuito de retirar o excesso de solvente.

\section{Calorimetria exploratória diferencial (DSC)}

Foi utilizado o calorímetro da marca TA Instruments modelo 2910 As amostras foram aquecidas de $25^{\circ} \mathrm{C}$ até $150{ }^{\circ} \mathrm{C}$ a $20{ }^{\circ} \mathrm{C} / \mathrm{min}$, em seguida houve o resfriamento de $150{ }^{\circ} \mathrm{C}$ até $-100{ }^{\circ} \mathrm{C}$ a $20^{\circ} \mathrm{C} / \mathrm{min}$. Houve então uma isoterma de 3 minutos com novo aquecimento de $-100{ }^{\circ} \mathrm{C}$ até $200{ }^{\circ} \mathrm{C}$ a $20^{\circ} \mathrm{C} / \mathrm{min}$.

\section{Microscopia eletrônica de varredura}

A morfologia das amostras foi analisada por meio de microscopia eletrônica de varredura (MEV), utilizando um
Microscópio Eletrônico de Varredura modelo JSM-5900LV (JEOL Ltd, Akishima, Japan), do Laboratório Nacional de Luz Síncroton (LNLS).

\section{Resultados e Discussão}

\section{Espectroscopia na região do infravermelho}

Foram realizadas análises por espectroscopia na região do infravermelho das amostras dos plastificantes puros: DOP, DOA, OVM e OVME, cujos espectros são mostrados na Figura 4 e os dados referentes às absorções estão citados na Tabela 3.

Para os espectros (a) e (b) da Figura 4, referentes aos óleos vegetais, são observadas bandas de absorção do grupo $\mathrm{C}=\mathrm{O}$ referente aos ésteres alifáticos ocorrendo na região de $1750-1735 \mathrm{~cm}^{-1}$ e também a freqüência de vibração do grupo (C-O-C), de ésteres, na região de 1200 e $1300 \mathrm{~cm}^{-1[17]}$.

No espectro (b) ainda são observadas bandas na região de 740 e $760 \mathrm{~cm}^{-1}$, referentes aos grupamentos cis e trans-epóxi, respectivamente, que aparece também como um ombro na banda da região de $890 \mathrm{~cm}^{-1[18]}$.

Nos espectro (d) é observada a banda na região entre 740-780 $\mathrm{cm}^{-1}$ correspondente ao benzeno 1,2 - dissubstituído referente ao DOP, o qual não é visto no espectro (c), referente ao $\mathrm{DOA}^{[10]}$. No espectro (d) também são observadas deformações axial das ligações carbono-carbono do anel nas regiões de 1.600 a $1.585 \mathrm{~cm}^{-1}$, referenciando-se o grupo aromático presente no plastificante DOP.

A Tabela 3 apresenta os principais grupamentos observados para os diferentes plastificantes utilizados neste trabalho, assim como as atribuições.

\section{Ensaios de tração}

A Figura 5 ilustra valores médios e os respectivos desvios padrão das propriedades de módulo de elasticidade, resistência à tração e alongamento na ruptura das diferentes formulações.

Pode-se observar pelaFigura 5, que os valores de resistência à tração entre as formulações com os diferentes plastificantes não apresentaram diferenças significativas. Quanto ao módulo de elasticidade das formulações, observou-se que o plastificante OVM apresentou média superior às demais contendo DOP, DOA e OVME, influenciada provavelmente pela exsudação verificada nesta composição.

Por outro lado os resultados de alongamento na ruptura mostram que os plastificantes OVM e OVME apresentaram maiores valores da propriedade frente ao DOP e ao DOA, sendo este último o valor mais baixo. Estes resultados evidenciam que o plastificante OVME apresenta maior eficiência na plastificação. Possivelmente a estrutura química deste promove maior interação entre a matriz polimérica e o plastificante, bem como um maior afastamento entre as cadeias do polimero $^{[7]}$. Já o plastificante OVM apresentou 


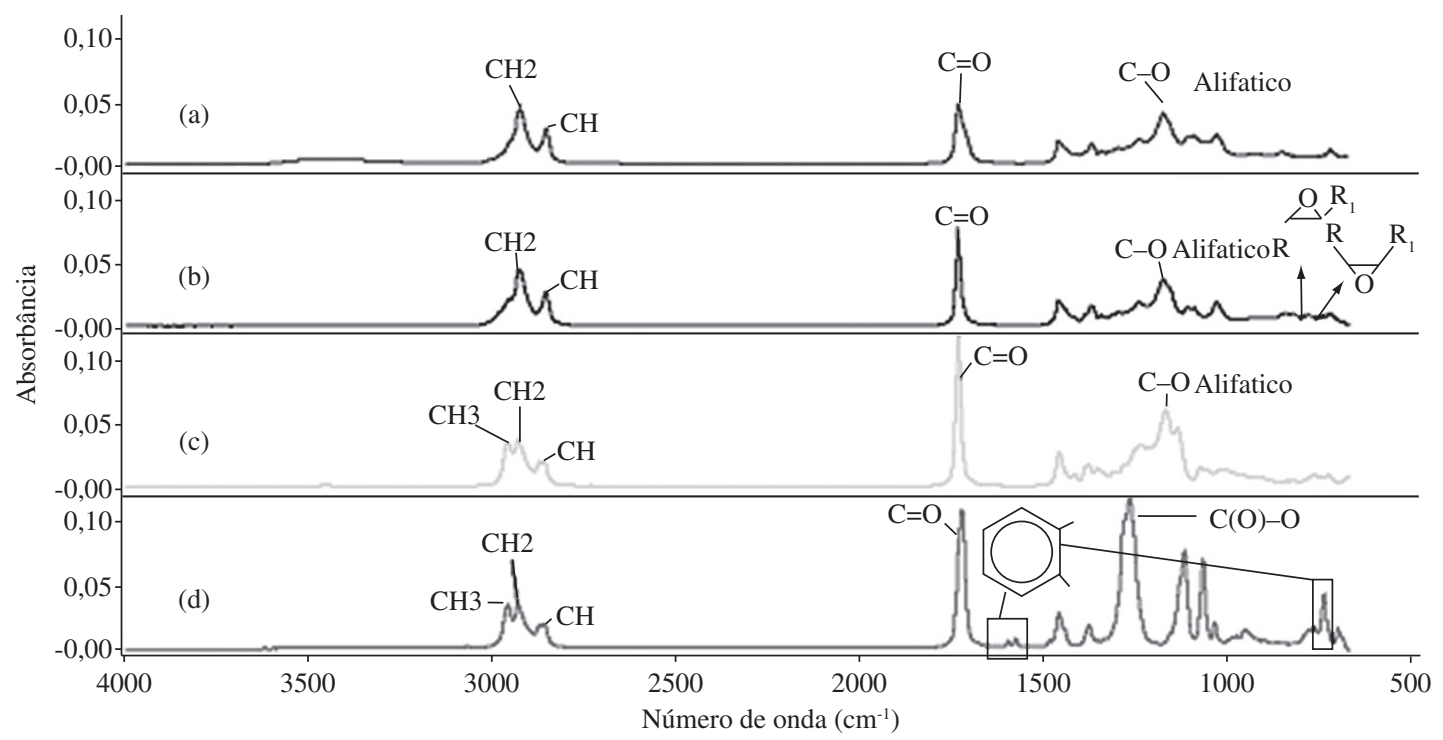

Figura 4. Espectros na região do infravermelho e principais bandas associadas aos grupamentos observados para os diferentes plastificantes utilizados: a) OVM; b) OVME; c) DOA; e d) DOP.

Tabela 3. Principais grupamentos observados para os diferentes plastificantes utilizados.

\begin{tabular}{ccc}
\hline Estrutura & $\begin{array}{c}\text { Região de } \\
\text { absorção }\left(\mathbf{c m}^{-1}\right)\end{array}$ & Deformação \\
\hline $\mathrm{C}=\mathrm{C}$ (anel) & $1.605-1.466$ & Axial \\
$\mathrm{C}-\mathrm{C}$ (anel) & 687 & $\begin{array}{c}\text { Angular fora do } \\
\text { plano }\end{array}$ \\
$\mathrm{C}=\mathrm{O}$ & $1.750-1.735$ & Axial \\
$\mathrm{C}-\mathrm{O}$ & $1.300-1.000$ & Axial assimétrica \\
\hline
\end{tabular}

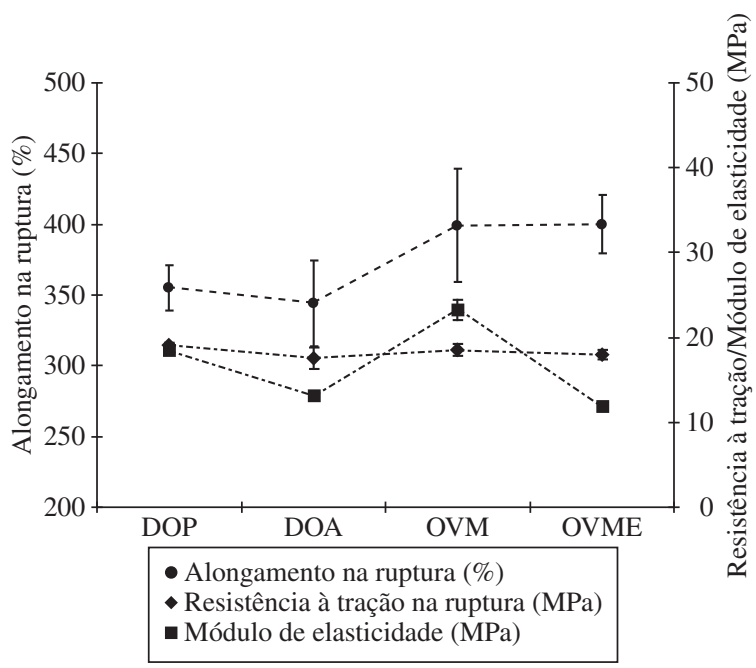

Figura 5. Propriedades mecânicas de resistência à tração, alongamento na ruptura e módulo de elasticidade das diferentes formulações.

maior valor de desvio padrão na característica de alongamento, sugerindo heterogeneidade nas amostras, provavelmente pela exsudação observada nesta formulação.

As propriedades mecânicas dos compostos flexíveis de PVC estão diretamente relacionadas à dureza das formulações, associadas à estrutura química e quantidade dos plastificantes ${ }^{[7]}$. Plastificantes de maior massa molar e contendo grupos laterais volumosos apresentam menor eficiência de plastificação. A variação na estrutura química do plastificante, como polaridade e ramificação, podem apresentar também influência sobre as propriedades mecânicas, como alongamento na ruptura ${ }^{[7]}$.

Da mesma forma, avaliando-se diferentes composições com mesma dureza e plastificantes de uma mesma família química, não são observadas diferenças significativas nas propriedades de alongamento e resistência à tração na ruptura, mesmo variando a massa molar dos plastificantes. Quando se altera a família química do plastificante, de um ftalato para um éster epóxi, por exemplo, as propriedades de alongamento na ruptura são significativamente alteradas ${ }^{[19]}$.

Os resultados de módulo de elasticidade entre as composições mostraram que existe correlação desta característica com a dureza das formulações, ou seja, a formulação contendo o OVM apresentou maior valor de módulo que as demais. Da mesma forma, os valores para a dureza determinados para esta formulação também mostraram um valor superior. Por outro lado, a formulação com OVME apresentou os menores valores de módulo de elasticidade e de dureza. Para o setor plástico é comum o termo "módulo de rigidez" como referência ao módulo de elasticidade, uma vez que pode se referir indiretamente à propriedade de dureza/rigidez.

\section{Propriedades reológicas}

A Figura 6 apresenta as curvas reológicas das diferentes formulações na qual observa-se que a formulação com o DOP apresenta maior torque de estabilização que as demais formulações, isto pode estar relacionado à maior viscosidade do fundido. Já a formulação com DOA apresenta menor torque de estabilização, conseqüentemente, menor viscosidade do fundido. 


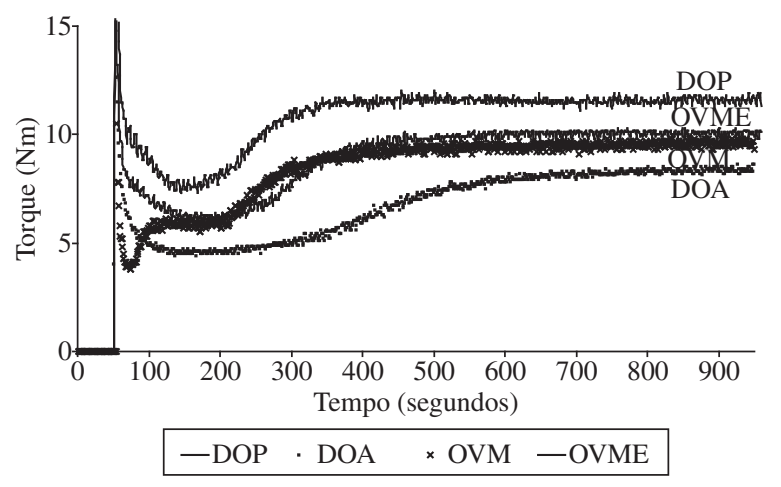

Figura 6. Curvas de torque em função do tempo para formulações de PVC com diferentes plastificantes.

Plastificantes e lubrificantes na matriz do PVC, durante a etapa de gelificação do composto, tendem a reduzir o atrito entre as partículas e/ou entre estas e o equipamento, a depender da natureza química destes aditivos ${ }^{[1]}$. Assim, as formulações contendo DOA, OVM e OVME apresentaram menores torques de estabilização em relação ao DOP devido aos fatores físico-químicos, como por exemplo, a viscosidade dos plastificantes puros que são menores que as do DOP. Outro efeito que também pode contribuir para a queda no torque de estabilização (viscosidade do fundido) é a presença de lubrificantes na matriz polimérica. Estes podem atuar nas ligações intermoleculares do PVC (dipolo-dipolo e forças de van de Waals) ou entre as partículas e o metal do equipamento, reduzindo o atrito intramolecular ou material e equipamento.

Este mesmo efeito foi verificado por Costa e Rosa ${ }^{[10]}$ no uso da PCL como lubrificante interno para o PVC em misturas preparadas entre estes dois materiais, que apresentaram queda no torque de estabilização.

\section{Dureza}

A Figura 7 apresenta os resultados de dureza dos diferentes compostos preparados.

A Figura 7 apresenta os valores de dureza das formulações de PVC com os diferentes plastificantes. A formulação OVME apresenta dureza próxima à formulação com DOA e $5,5 \%$ abaixo da formulação com DOP, mostrando seu maior poder de plastificação que o DOP. Já a composição com OVM apresentou dureza bem superior às demais, estando a $11 \%$ acima da OVME. Vale lembrar que o plastificante OVM, apresentou forte exsudação, comprometendo o resultado de dureza e a avaliação correta desta propriedade.

Zaioncz $^{[20]}$ avaliou a eficiência dos plastificantes e seu poder de solvatação na resina de PVC. Concluiu que quanto maior o poder de solvatação do plastificante, tanto maior será sua capacidade de flexibilização no PVC, ou seja, a dureza do composto flexível de PVC será dada pela quantidade do plastificante presente na formulação, sendo que, quanto maior sua eficiência ou poder de solvatação, menor a quantidade a ser utilizada.

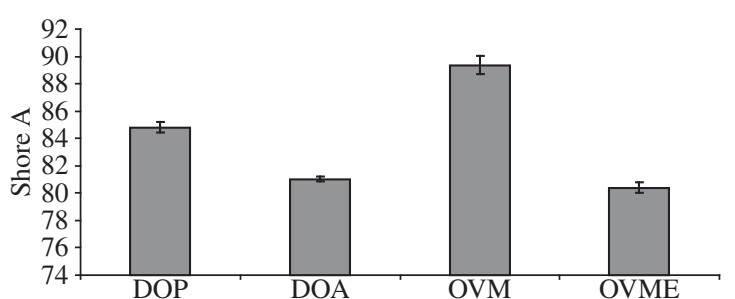

Figura 7. Dureza Shore A para as formulações de PVC com diferentes plastificantes.

\section{Resistência química à n-heptano}

A Figura 8 apresenta os resultados de extração através do solvente n-heptano para as diferentes formulações avaliadas, sendo que os plastificantes DOA e OVM sofrem maior variação de massa que as formulações com DOP e OVME. A diferença entre os dois primeiros e os últimos é significativa e chega a ser maior que $100 \%$. Sugere-se que o DOA e o OVM apresentam menor interação com a matriz de PVC e, possivelmente, melhor "afinidade" pelo solvente, o que facilita sua extração pelo n-heptano. Esta verificação também foi apontada por Titow ${ }^{[6]}$, que verificou que os plastificantes da família dos adipatos apresentam maior volatilidade e menor resistência à extração por água e solventes que os ftalatos, enquanto que os ésteres epoxidados apresentam boa resistência à extração para estas substâncias.

O uso das composições com DOA e OVM em formulações para contato com alimentos ficaria comprometida pela maior perda de plastificantes para o meio, o que certamente comprometeria a qualidade do alimento. A migração ou exsudação de plastificantes para o meio não compromete apenas os alimentos mas também outras partes de um produto, como é o caso de portas de refrigerados, que podem sofrem ataque do plastificante em suas partes fabricadas com o poli(estireno), $\mathrm{PS}^{[6]}$.

\section{Calorimetria exploratória diferencial (DSC)}

As curvas térmicas (termogramas) obtidas no ensaio de DSC para as diferentes formulações de PVC são apresentadas na Figura 9.

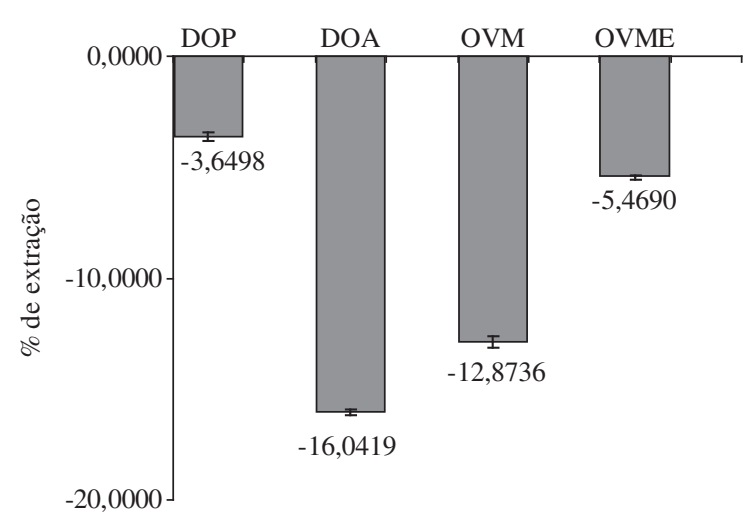

Figura 8. Variação de massa pela ação do solvente n-heptano à temperatura de $23{ }^{\circ} \mathrm{C}$ por 168 horas para as diferentes formulações. 
Verifica-se que, na Figura 9, a temperatura de transição vítrea (Tg) característica da resina de PVC puro, ficou situada em $83,3{ }^{\circ} \mathrm{C}$, valor este similar ao reportado por Titow ${ }^{[6]}$ que varia entre 80 a $84^{\circ} \mathrm{C}$.

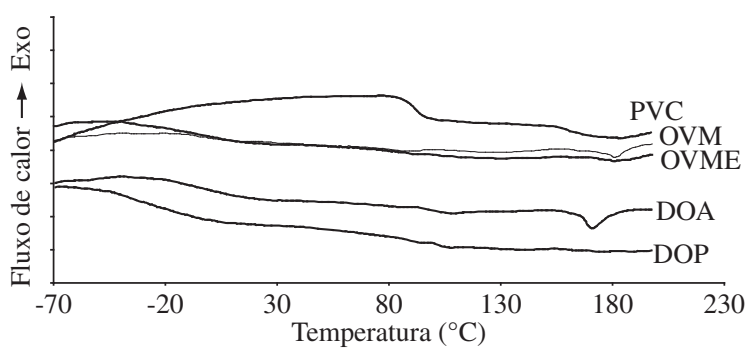

Figura 9. Termogramas obtidos para o PVC puro e para as formulações de PVC com os diferentes plastificantes.

Tabela 4. Valores de temperatura de transição vítrea $(\mathrm{Tg})$ para as formulações de PVC.

\begin{tabular}{cc}
\hline Material & $\mathbf{T g}\left({ }^{\circ} \mathbf{C}\right)$ \\
\hline PVC puro & $83,3{ }^{\circ} \mathrm{C}$ \\
Formulação com DOP & $-44,3{ }^{\circ} \mathrm{C}$ \\
Formulação com DOA & $-29,7{ }^{\circ} \mathrm{C}$ \\
Formulação com OVM & $-10,6{ }^{\circ} \mathrm{C}$ \\
Formulação com OVME & $-40,1^{\circ} \mathrm{C}$ \\
\hline
\end{tabular}

Com a adição dos plastificantes, há uma redução significativa da $\mathrm{Tg}$ do material ${ }^{[6]}$, cuja variação do fluxo de calor se apresenta anterior à do PVC puro, conforme apresentado na Tabela 4.

Observa-se na Figura 9 que os termogramas relativos às composições contendo os plastificantes estudados apresentam faixas de temperatura de transição largas, sugerindo que exista microheterogeneidade entre os plastificantes e a matriz de PVC.Esta mesma observação é feita no trabalho de Robeson ${ }^{[21]}$ sobre materiais que apresentam microheterogeneidade em sua estrutura analisada por meio de DSC.

\section{Microscopia eletrônica de varredura}

$\mathrm{Na}$ Figura 10 são apresentadas as fotomicrografias da superfície das diferentes formulações em diferentes aumentos cujas observações se concentradas na formação de pequenas gotículas, apontadas pelas setas na fotomicrografia com aumento de 2.000 vezes na formulação com o OVM. Tais gotículas sugerem a migração do plastificante para a superfície da amostra, observação esta não verificada nas demais formulações. Titow ${ }^{[6]}$ avaliou que a compatibilidade com a matriz, no caso o PVC, é característica fundamental para uma dada substância ser considerada plastificante para este polímero. Esua permanência de maneira estávelé característica

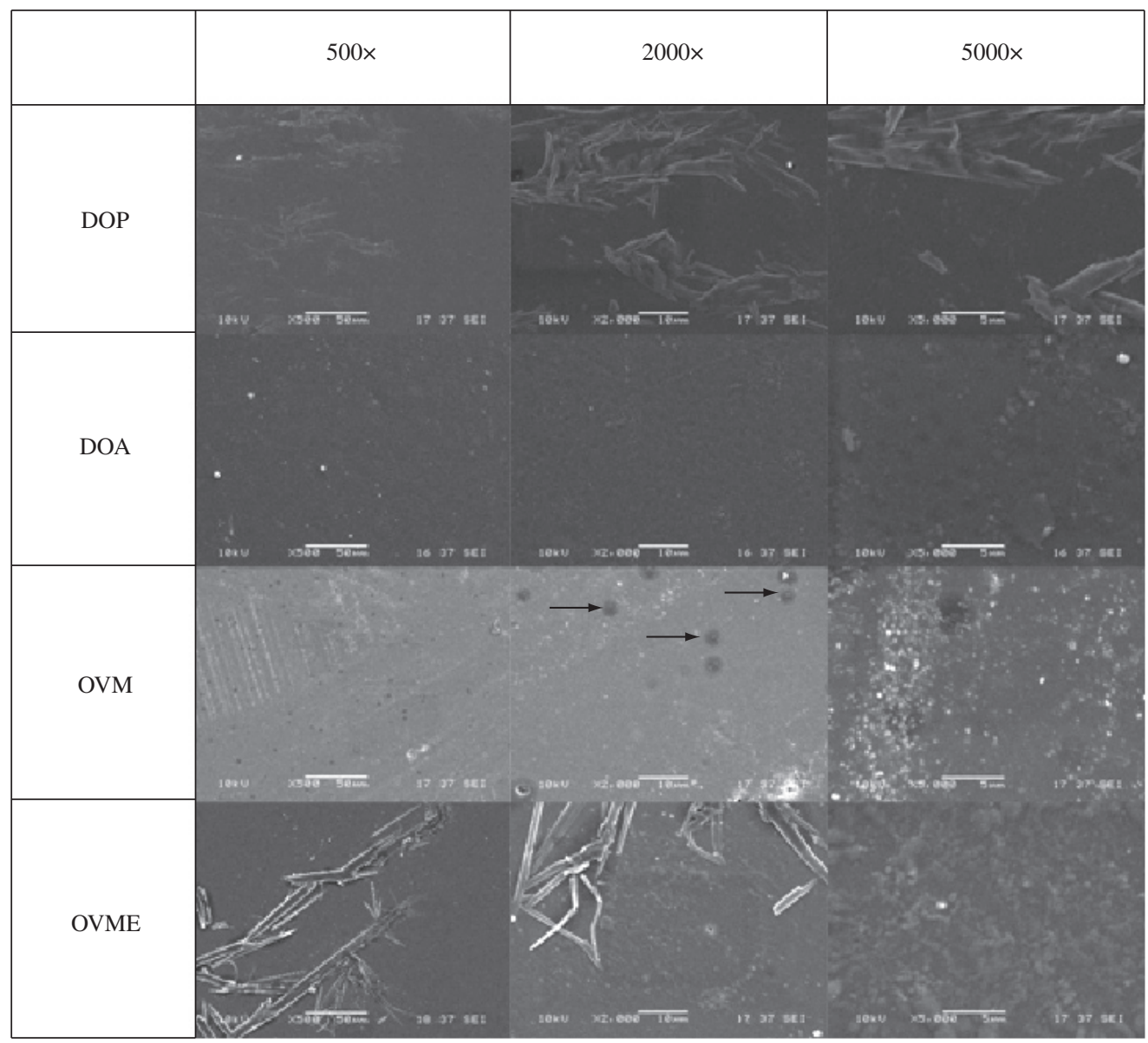

Figura 10. Fotomicrografias de superfície das diferentes formulações com os diferentes plastificantes. 
de extrema importância para o desempenho desta formulação, evitando assim uma possível exsudação. No caso específico da composição com o OVM esta propriedade não é atendida, e a exsudação acaba por ocorrer. Assim, o acondicionamento destas amostras sempre esteve reservado e fora do contato com as demais, a fim de evitar uma possível contaminação. Quanto às demais fotomicrografias não são verificadas nenhuma diferença significativa entre as formulações com os diferentes plastificantes. Observa-se a formação de estruturas orientadas na fotomicrografia do OVME que podem ser oriundas de defeitos ou resíduos das matérias primas.

\section{Conclusões}

O plastificante OVME apresentou excelentes características físicas, químicas e visuais quando comparado aos plastificantes tradicionais, como o DOP e DOA, em compostos flexíveis de PVC.

Entre as formulações com DOP e OVME, as propriedades mecânicas de resistência à tração e alongamento na ruptura e módulo de elasticidade se mostraram similares. O mesmo comportamento pode ser verificado nas propriedades de resistência química ao n-heptano, bem como no processamento (gelificação e fusão). Contudo, o plastificante OVME se mostrou mais eficiente na plastificação das formulações do PVC, evidenciado pelos valores médios de dureza Shore A inferiores do que aquelas obtidas para as formulações em que o DOP foi empregado. O plastificante OVM apresentou forte exsudação o que provocou uma maior variação nas propriedades estudadas no período inicial dos envelhecimentos, no entanto, após a fase da exsudação do plastificante, as propriedades se mantiveram.

É possível o uso de plastificantes de fontes renováveis em substituição aos plastificantes tradicionais, como o DOP e DOA, em formulações de PVC, conforme verificados neste estudo com o uso do OVME.

\section{Agradecimentos}

Os autores agradecem à Braskem, LNLS, Universidade Federal do ABC, Universidade Federal do Paraná, Universidade Estadual de Campinas, Universidade São Francisco e CNPq.

\section{Referências Bibliográficas}

1. Rodolfo Jr., A.; Nunes, L. R. \& Ormanji, W. - "Tecnologia do PVC". 2 ed. Pró Editores Associados, São Paulo (2006).

2. Heudorf, U. et al. Phthalates: Toxicology and exposure. International Journal of Hygiene and Environmental Health, 15, October (2007).

3. PVC. Disponível em:<http//www.institutodopvc.org/ publico $>$. Acesso em: agosto 2008 .
4. Nass, L. I. \& Heiberger, C. A. - (Ed.). "Encyclopedia of PVC: Conversion and Fabrication Processes". 2 ed. Marcel Dekker, New York (1998).

5. Wickson, E. J. - "Handbook of polyvinyl Chloride Formulating”. 2 ed. John Wiley \& Sons, New York (1993).

6. Titow, W. V. - "PVC Technology". Ed. Elsevier Applied Science Publishers, London (1984).

7. Wilson, A. S. - "Plasticisers Principles and Practice". The Institute of Materials, Cambridge (1995).

8. Pedrozo, T.;Zawadski,S.\& Ramos,L. - "Desenvolvimento de plastificante alternativo para PVC à partir do óleo de milho". Relatório de atividades. Universidade Federal do Paraná, Departamento de química, Curitiba (2007).

9. Krauskopf, L. G. \& Godwin, A. L. - Plasticizer Factors Influencing Take-Up by PVC Resins. Journal of vinyl $\&$ additive technology, 5, p.107-112 (1999).

10. Costa, A. \& Rosa, D. S. - "Desenvolvimento de blendas PVC/PCL e caracterização das propriedades mecânicas, térmicas e de biodegradação", Tese de Mestrado, Universidade São Francisco, Itatiba, Brasil (2006).

11. BRASKEM. - "Folha de dados. Policloreto de vinila PVC - Norvic ${ }^{\circledR}$ SP 1300HP”. Disponível em: <http:// www.braskem.com.br>. Acesso em: 30 junho 2007.

12. SCANDIFLEX. Disponível em:<http://www.scandiflex. com.br/principal.htm.consulta em julho/2007>.

13. American Society for Testing and Materials. "ASTM D-638: Standard test method for Tensile Properties of Plastics". West Conshohocken (2003)

14. American Society for Testing and Materials. "ASTM D-2396: Standard Test Methods for Powder-Mix Time of Poly(Vinyl Chloride) (PVC) Resins Using a Torque Rheometer". West Conshohocken (2004).

15. American Society for Testing and Materials. "ASTM D2240: Test Method for Rubber Property - Durometer Hardness". West Conshohocken (1993).

16. Agência Nacional de Vigilância Sanitária - ANVISA. Disponível em :<http://www.anvisa.gov.br/alimentos/ legis/index.htm>. Acesso em: 17 março 2008

17. Silverstein, R. M.; Bassler, G. C. \& Morrill, G. C. - "Identificação Espctrométrica de Compostos Orgânicos". 5 ed. Editora Guanabara Koogan, Rio de Janeiro (1999).

18. Rocha, T. et al. Estudo da modificação química do polidienos do tipo SBR e BR. Polímeros: Ciência e Tecnologia, 14, p.318-321 (2004).

19. Krauskopf, L. G. - How about alternatives to phthalate plasticizers. Journal of Vinyl \& Additive Technology, 9, p.159-171 (2003).

20. Zaioncz, S. - "Estudo do efeito da plastificação interna do PVC quimicamente modificado", Tese de Mestrado, Universidade Federal do Paraná, Curitiba (2004).

21. Robeson, L. M. - "Polymers Blends: a compreensive review". Carl Hanser Verlag, Inc. Munich (2007). 